\title{
HUMAN CHOICE AND ICT POLICY: INTRODUCTION TO THE HCC8 CONFERENCE PROCEEDINGS
}

\author{
Chrisanthi Avgerou \\ London School of Economics and Political Science, UK \\ Matthew L. Smith \\ International Development Research Centre, Canada \& \\ London School of Economics and Political Science, UK \\ Peter van den Besselaar \\ University of Amsterdam \& \\ Rathenau Institute, The Netherlands
}

\section{Introduction}

Since its launching in 1974, the Human Choice and Computers (HCC) series of conferences of the IFIP Technical Committee 9 (TC9) ${ }^{1}$ has provided a forum for the study of the multiple facets of the dynamics of social change associated with information and communication technologies (ICTs). These conferences have captured the unfolding hopes and concerns about the interplay between the technologies we construct and our personal lives, organisations, and social institutions. Whether the message voiced by individual authors is optimistic and positive about the emerging socio-technical arrangements or worrying and critical, the "human choice" concept has always been pivotal in the discussions of the HCC conferences.

In HCC studies, as well as in kindred research streams such as Social Informatics [6, 17], Participatory Design [10, 23], and the Social Study of ICT [3], the shaping of ICT-mediated social arrangements is seen as resulting from the interaction among a broad range of categories of human actors. Early focus on engineers and managers of the innovating work place, each seen as endowed with the formal technical logic of their profession, has expanded to address the pervasiveness of ICT-mediated practices that comprise the so-called information society. Computer users juggling with multiple ICT artefacts at the work place, entrepreneurs taking risk with new-technology-incorporating products and processes, consumers, corporate executives creating competitive advantage with new business models, government regulators setting the norms of the innovation arena, NGO activists forging the values of ICT-mediated civil spaces, citizens

\footnotetext{
${ }^{1}$ The IFIP Technical Committee 9 (TC9) is dedicated to the study of the relationship of "Computers and Society" [http://is2.1se.ac.uk/tc9/]. See [22] for the proceedings of the first HCC conference.
}

Please use the following format when citing this chapter:

Avgerou, C., Smith, M.L. and van den Besselaar, P., 2008, in IFIP International Federation for Information Processing, Volume 282; Social Dimensions of Information and Communication Technology Policy; Chrisanthi Avgerou, Matthew L. Smith, Peter van den Besselaar; (Boston: Springer), pp. 1-13. 
exercising their democratic rights in ICT-mediated government institutions, are only some of the roles through which the information society play of the early $21^{\text {st }}$ century is enacted. HCC research deciphers the lines each of them performs, seeks to interpret their interests and, occasionally, exposes their unfulfilled role. It often witnesses conflicts, power dynamics, and the mismatch of bold rhetoric of revolutionary change with painstakingly slow action and reversals. Sometimes it dares to articulate recommendations, thus attempting to legislate either specific actor roles, or the direction of the enactment, though such attempts from scholars remain of dubious legitimacy and effectiveness within contemporary society [5].

Partly as a result of the broad scope of attention to multiple actors, the notions of choice and action have a broad meaning in HCC research. Choice is exercised not only in technical decision making settings, but in the streams of everyday practices of people's lives. The choices that construct ICT-mediated socioeconomic institutions involve tacit knowledge; they are not confined to formal cognitive processes. Moreover, socio-technical choices are not merely cognitive, they are to a large extent ethical in character [4], and involve emotional human capacities [9]. Action too is not limited to professional conduct informed by analytical design models and planning techniques; it is improvisational, idiosyncratic, deeply political and culturally conditioned. It should be noted that these notions of action that are increasingly prevalent in HCC conferences are congruent with the concepts of the mutual constitution of human agency and social structure [15], of technology and society [7, 18], and of the social dynamics of technical change $[13,24]$ that became prevalent in social sciences in the last decade of the twentieth century.

This book, drawing its chapters from the $8^{\text {th }} \mathrm{HCC}$ on the Social Dimensions of ICT Policy, follows the same conceptual direction, but focuses in particular on human choice and action pertaining national and supra-national policy, thus shifting attention to efforts of collective actors shaping macro-level processes: governments, regulating authorities, citizens, social institutions, industries, universities, civil society organisations, etc. Policy involves purposeful action in a large variety of forms: the setting of a vision, the identification of problems to be overcome or opportunities not to be missed, the drafting of legislation, the mobilization and allocation of resources, the efforts to win public opinion and mobilise public support, the negotiations on intended ends and available means, the organisation of "projects", and the monitoring of results. This is neither a prioritised nor an exhaustive list, but it is indicative of the visible aspects of a collective process that seeks to steer individuals, institutions and technologies towards particular ends. There is, of course, a less visible side of action accompanying policy, such as citizens' often silent behavioural positioning in relation to a government initiative, incremental institutional adjustments, covert alignments of agencies with diverse interests which translate policy initiatives and their intended outcomes differently from their declared logic and aspirations.

The significance of government action in fostering ICT innovation and enabling society to cope with the destructive consequences of its pervasive 
diffusion is well documented in a number of publications [12, 14, 16, 19, 21]. National and regional governments and international development agencies such as the World Bank, have pursued policies for the advancements of ICT in various sectors, mainly aiming at harnessing the potential of ICT for achieving economic growth. Many governments sought to promote the development of ICT industries. Examples of such policies are the efforts of European countries to develop computer hardware manufacturing in the 1980s [12], and more recently the efforts of developing countries to become competitive producers of software [1, 11].

Government policy for the development of ICT industries is debatable. In particular, policies designed to protect local producers from foreign competition have proved risky, often developing complacency of local ICT firms regarding innovation by providing them a captive market, while depriving domestic users of state-of-the-art technologies at internationally competitive prices. On the other hand, fostering an ICT industry synergistically with domestic users bears mutual benefits for the learning and the development of capabilities that are considered necessary for the contemporary economy. ${ }^{2}$ Thus, while particular protectionist policy interventions are controversial, there is a general consensus in the literature of industrial policy and economics of innovation that governments have a crucial role to play in creating the conditions for collaboration and competition among business firms producing and using ICT. Governments, for example, have a major role to play in securing the existence of a work force appropriately skilled for the knowledge economy, in regulating the providers - and in many cases providing themselves - telecommunications services, and in sponsoring R\&D. Moreover, as ICT users themselves, governments are directly collaborating with ICT industry, for example for developing information systems infrastructures for national health care, and therefore they are interested in achieving synergistic gains.

Less controversial is the view that government should be addressing the emerging social issues that accompany ICT innovation. To begin with, there is a widely held expectation that governments will take initiatives to enable their citizens to participate in the information society. For example, governments are expected to use ICTs to strengthen democratic processes through e-government services that improve the transparency and responsiveness of state agencies. And as the Internet becomes a fundamental means for information and communication, governments are also expected to act to avoid social exclusion that occurs from lack of access to ICT and from lack of capabilities to participate in ICT-mediated social and economic activities. Moreover, there is general agreement that governments have a major legislative role to play in order to introduce institutions required for the information society. Personal data protection is one such area. Intellectual property rights (IPR) for information and software industries is another.

\footnotetext{
${ }^{2}$ The literature on economics of innovation elaborates on policies aiming at developing capabilities through geographically located partnership $[2,8,20]$.
} 
However there is less agreement about the extent to which governments are equipped to do these tasks and about the strategies to be followed. Additionally, government policies addressing the social dimensions of the information society are neither distinct from economic policy concerns, nor politically uncontroversial. Governments often stifle the democratic potential of the Internet with censorship; IPR legislation becomes a social convention that prevents technologically possible free access to information and software; and data protection clashes with concerns of national security. The policy dilemmas are greater in poor countries, many of which have neither public resources, nor developed markets to provide required telecommunications infrastructures for the information society. Moreover access to technology infrastructure is of limited developmental potential when literacy and job opportunities in the information sector are lacking. The HCC8 is dedicated to the study of such policy issues, and the chapters in this volume amply demonstrate the dilemmas and controversies of this area.

\section{Overview of the chapters}

As in most conferences, individual contributions vary in terms of the extent to which they are theoretically and methodologically grounded and make convincing arguments. As editors of this volume of proceedings we were also aware that HCC conferences draw authors from a mix of academics', practitioners', and NGO activists' communities, each of them with their distinctive epistemic culture and rhetorical style. Each of the submitted papers was reviewed by two reviewers knowledgeable of its particular topic, as well as the conference programme chairs, and most of the accepted papers were revised substantially as a result of reviewers' comments and suggestions. In the resulting book some papers present well articulated, theoretically and empirically supported arguments in the contemporary academic tradition; others voice concerns or shed light on particular issues that need closer investigation and theoretical comprehension. Some chapters present research in progress, which although has not produced yet definitive conclusions, raises awareness of particular aspects of the emerging information society and stimulates consideration of appropriate policy action. In addition, we include in this book outlines of three panel discussions. We consider all these types of contribution valuable for the continuing effort to understand the nature and scope of human choice in the shaping of the information society.

We provide below an overview of the chapters we drew from the conference papers. The first chapter is the keynote presentation by Robin Mansell. Appropriately for a conference taking place in Africa, Robin Mansell focuses on the policy challenges confronting low income countries. She draws from her involvement in international networks and institutions that influence policy on media and communications - a policy area overlapping with ICT policy within the broader arena of efforts regarding the "Knowledge Society" - and proposes a research framework to support policy interventions that enable well being through 
sustainable development. Her framework suggests the need for research on human rights, communication and information, access and literacies, participatory communication, representation and critical assessment of strategic communication and information policies, and indicators of knowledge societies.

The rest of the book is structured in four Parts. Parts 1 to 3 contain chapters on the following broad thematic categories: the shaping of national and international ICT policies and their effects; harnessing the empowering capacity and ICT; and the shaping of the institutions of the information society. The fourth Part contains the panel descriptions.

\section{Part 1: The shaping of national and international ICT policies and their effects}

The chapters of this Part discuss specific cases or areas of national and international ICT policy, showing various facets of the policy making. They shed light on the way policies for the deployment of ICT and the mobilization of required resources and action are formed. The picture that emerges shows a variety of interactions across different levels of governance.

In The argumentative structure of spatial data infrastructure initiatives in America and Africa, Yola Georgiadou and Vincent Homburg point to the powerful influence of "myths", abstract tales that are neither true nor false, but rather are living or dead. These myths, in this case about spatial data infrastructures in Africa, are tales regarding the intention and purposes of new technologies that motivate and pervade policy. As the authors detail in their analysis, such myths can travel through time and space, from one context to another, mutating along the way as they are edited to account for contextual differences and to maintain legitimacy.

Ioanna Chine, in ICT policy as a governable domain: the case of Greece and the European Commission, illustrates how the development of a national ICT policy is sometimes subject to and interacts with controlling forces beyond the traditional state boundary. Drawing from Foucault's notion of governmentality, Chini argues that the Greek national government was subject to techniques of control from the supra-national European Commission that regulated and engendered self-regulation within the Greek government with respects to ICT policy. The end result, she argues, is a Greek ICT policy that is effectively shaped by these techniques to fit the strategic vision of ICT policy held in the Eurpoean Commission.

The relationship between Greek ICT policy and European policy is also examined in the next chapter, National variations of the information society, by Dimitris Boukas, who takes a different theoretical perspective from that of Chini, considering Greece as a case of semi-peripheral, middle-income countries. Boucas analysis of the Greek case draws from historical sociology to show the creation of differentiated national information society features that result from the interaction 
of the state and the national economy and society with global information society processes.

In Technology, globalisation, and governance: research perspectives and prospects, Diego Navarra and Tony Cornford discuss the use of ICT in government organisations as a phenomenon which transcends the nation state, manifesting a distinctive problematisation of the nature of citizenship, statehood and, citizen/state relations. This phenomenon, they argue, is central to the contemporary world and as yet has not received much attention in the literature. To compensate for this gap, they propose several research perspectives that might help to increase our understanding of the many different aspects of this phenomenon, including Actor-network Theory, New Public Management, and Transaction Cost theory.

In Globalisation and national security issues for the state: implications for national ICT policies, Jackie Phahlamohlaka examines policy concerns associated with security threats that emerge due to the increasingly interconnected nature of computer neworks, and the penetration of these networks into the social, political, and economic activities of a state. In this chapter, Phahlamohlaka provides a novel framework to begin to grasp the different types of national security threats that have evolved with globalisation. Following this, he explores the potential implications for ICT policy and makes an urgent call for more research in this rapidly changing and still underdeveloped area.

In Next generation ICT policy in South Africa: towards a human developmentbased ICT Policy, Walter Brown and Irwin Brown discuss ICT policy in terms of assumptions and values as to the ways and means that new technology can contribute to the development of a country. They point out that, like any policy, a state's ICT policy will have distributional impacts, intended or unintended, that benefit some and disadvantage others. As Brown and Brown document, despite significant advances in ICT diffusion in South Africa, the advantages of ICT have not been spread evenly among the citizens, for a variety of reasons. To rectify this situation for the next generation of ICT in South Africa, the authors propose that the various terminologies used to describe the various technologies should be collapsed into the term telecommunications. They argue that this would be a start towards the development of a simple and effective ICT policy that places human development at the core: a human development-based ICT policy.

Successful ICT diffusion and uptake depends, as other chapters in this volume argue, upon coherent policy that is not only well developed, but also well implemented. In his chapter, Challenges of ICT policy for rural communities: a case study from South Africa, Mpostol Jeremia Mashinini examines the rural community of Dr. S.J. Moroka in South Africa to uncover a myriad of challenges that need to be addressed to enable this community to derive human development benefits from new ICTs. Interestingly, the central challenge that Mashinini's study reveals is that, for a variety of reasons discussed in this chapter, a majority of the ICT policies designed to address these challenges were simply not being implemented. 


\section{Part 2: Harnessing the empowering capacity and ICT}

The chapters of this Part examine efforts to exploit the potential of ICT to empower the population of a country to participate in the emerging information society and improve their well being. There are various areas of action to that end, including government initiatives to overcome the digital divide problem, the construction of information resources to support health care services, and education initiatives aimed to develop the technological and social capabilities for the information society.

Panayiota Tsatsou, in her chapter Digital divides and the role of policy and regulation, reviews current understanding of the digital divide problem and the role of policy and regulation for achieving digital inclusion. She presents data from interviews with policy makers, researchers, Internet service providers, and business agencies in Greece, which is a country with persistently low Internet adoption. Her analysis reveals problems related with culturally embedded decision making mechanisms. Thus Tsatsou concludes by identifying the need for socially accountable policies and regulations aiming to alter the traditional bureaucratic and techno-phobic culture, that her analysis suggests to be an obstacle to change, and to allow more scope for market forces.

In Empowerment through ICT: a critical discourse analysis of the Egyptian ICT Policy, Bernd Carsten Stahl shows that the rhetoric of ICT policy statements doesn't always match the reality on the ground. Using critical discourse analysis Stahl examines Egypt's ICT policy documents through the lens of critical theory to uncover the rhetoric and underlying intentions. In particular, he contrasts the ICT policy rhetoric and Egyptian social realities in the areas of empowerment and education. Stahl finds that the discourse of empowerment through ICT is not matched by equivalent government action and thus at best shows a lack of sincerity or at worst hides an oppressive intention that works to actively disempower citizens. Researchers and practitioners are advised to think critically when using such policy documents.

In Egyptian women artisans: ICTs are not the entry to modern markets, Leila Hassanin shows that ICT policy that establishes an enabling environment for ICT usage and human development benefits is a significant factor, but is certainly not the only one. Certain activities, such as selling crafts at a local market do not easily scale up to e-commerce, especially internationally, which requires a level of funding and a whole new set of technical, legal, and other expertise that are generally not available to the average SME. In this chapter, Hassanin's case study of Egyptian women craftmakers illustrates these challenges, and counters the fundamental assumption that ICT access will open up new markets for micro- and small businesses, enabling them to expand their sales and income.

Solomon Bishaw, in his chapter Institutional strategies towards improving health information systems (HIS) in Sub-Saharan Africa, discusses the challenges confronting the development of information infrastructures for health care. He identifies the difficulty of effective participation of relevant actors in the 
endeavours for the development of hospital information systems as a major obstacle, and draws from institutional theory to analyse the institutional processes and pressures that constrain, construct and empower participation.

In A human environmentalist approach to diffusion in ICT policies, Elaine Byrne and Lizette Weilbach remind policy makers that ICT policy needs also to be cognizant of the variety of contextual factors that make ICT diffusion and adoption a complex, and non-linear, process. Standard IT diffusion theory that gives credence to this approach apparently assumes uni-directional causality between the implementation of technology and its adoption. In contrast, Byrne and Weilbach present an extended and holistic model of IT diffusion based upon the human environmental model. Such a model, they argue, is more appropriate to capture the complex dialectical interactions of technology and context during diffusion.

In ICT and socio-economic development: a university's engagement in a rural community in Yola, Nigeria, Jainaba Kah and Muhammadou Kah explore theoretically and empirically the role of universities in the diffusion and use of ICT for socio-economic development. The authors cover a broad range of theoretical ground linking ICT, universities, and development including: economic theory on the role of universities in economic development, ICT and poverty alleviation, and a consideration of various factors that impede developmental outcomes from ICT interventions in Africa. To ground the discussion, the authors provide a detailed case description of the activities of one University in northern Nigeria aimed at promoting socio-economic development through, in particular, fostering increased techno-entrepreneurship and engaging with the community and industry.

In the last chapter of this Part, Lessons from a dropped ICT curriculum design project: a retrospective view, Roohollah Honarvar documents the development and disintegration of an attempt to develop a nationwide ICT curriculum for universities in Iran. Honarvar identifies a series of issues that emerged during the course of the project that eventually led to its termination despite a significant investment: the relatively rapid nature of change of ICT necessitating constant revision of the curriculum, the inability to provide the requisite flexibility due to centralised planning approach, lack of social orientation of ICT professionals, and the difficulties locating qualified lecturers to teach the curriculum. While these issues are specific to the Iranian context, they are also encountered by other countries looking to develop an ICT curriculum. Drawing from his experience, the author offers a series of potential solutions to these issues.

\section{Part 3: The shaping of the institutions of the information society}

The making of the information society requires new institutional mechanisms across a broad range of domains of human activity. The chapters in this Part discuss the formation of several such mechanisms: the governance of the Internet, legal regimes for accessing and using electronic entities such as software and 
academic publications, new forms of banking, social networking for various social causes, measures of the information society. They reveal deep controversies and contestations and, appropriately, some authors follow critical theoretical perspectives to analyse the areas of action they researched.

Jacques Berleur, in his chapter 15 years of ways of Internet governance: towards a new agenda for action, deconstructs numerous official publications and declarations that have been contributing to the shaping of the governance regime of the fundamental technology infrastructure of the information society: the Internet. He is skeptical of the emphasis given to self-regulating market forces, raising concern that such a regime might not realize the "people centred" information society that is often presented as the desirable end of government policy. He points out the "multistakeholder" approach which is stressed within the much publicized World Summit for the Information Society forums, but which "is still to find its full meaning".

In Governmental policies for ICT diffusion and leadership legitimacy in grassroots movements, Magda Hercheui shows that ICT policy may result in unintended consequences that adversely impact the goals of the policy itself. Drawing on institutional theory, Hercheui's study documents one such unintended consequence of an ICT policy to fund ICT usage by informal environmental education groups in Brazil. While ICT usage by these informal communities was enhanced, the conditionalities placed upon the funding resulted in a significant centralizing shift in their decision-making structures. This shift worked to counteract their original intention of non-hierarchical structures based on democratic participatory ideals. Interestingly, these structural changes proved durable enough to last beyond the funding period. Consequently, Hercheui advises that we need to be especially aware of how ICT policies influence the governance structures of civil society organisations so that citizens can ensure that new ICT policy and democratic aspirations remain compatible.

In Examining trust in mobile banking transactions: The case of M-PESA in Kenya, Olga Morawczynski \& Gianluca Miscione present their research in progress that examines the crucial role that interpersonal and institutional trust plays in a case of the use of a new mobile banking (m-banking) system in Kenya. Their preliminary findings suggest that while interpersonal trust in the agents representing the m-banking system is low, use still remains high due to institutional trust in the well-established mobile service provider.

Farid Shirazi, in Social networks within filtered ICT networks: a case study of the growth of Internet usage within Iran, describes how ICTs, such as blogs and mobile SMSs, are being used in Iran as a space for open social, cultural, political discourse in ways that otherwise were not possible. In response, however, the Iranian government has developed a sophisticated Internet censorship systems and have restricted ICT diffusion. This, Shirazi argues, has effectively restrained the growth and use of the Internet and inhibited civil freedoms, leaving Iran lagging considerably behind other countries in the region. 
The working assumption of Kay Kimppa in A no-IPR model as solution to reuse and understanding of information systems is that, much like how intellectual property rights (IPR) protection makes the purchasing of drugs unaffordable to many lower-income countries, software intellectual property rights can inhibit the ability of organisations, especially small and micro-enterprises with little resources, to take advantage of highly useful software. Kimppa argues in this work-in-progress chapter, that the current software IPR regime inhibits the reuse of software as well as the understanding that users have of the system. To counter the current regime, Kimppa proposes a no-IPR model to replace the current IPR legislation.

In Measuring information societies for development: a critical study of the Infostate framework, Anouk Mukherjee critically examines the assumptions behind a framework that attempts to quantify and monitor the information society status of different countries with the goal of providing policymakers with the information needed to guide policy and investment decisions. Such frameworks and measurements are generally considered useful, as Robin Mansell suggests in her chapter: if states wish to determine ICT policy to bridge the digital divide and advance towards the information society, based upon empirical evidence, it is helpful to have measurement frameworks to gauge the current status of different states. However, such frameworks may oversimplify the process of the formation of knowledge societies and indeed mislead the policy making effort. Mukherjee takes the Infostate framework to task for its highly instrumental orientation and makes an argument for more multidisciplinary approaches to capturing the information society phenomena.

Mathias Klang, in Open access barriers: an action research, presents the first stage of research that explores the challenges of obtaining universal access to information. Klang points out that the current system of journal publication and subscription is increasingly inhibiting access to scientific knowledge, especially scholarly journals. To combat this, an open access movement is pushing for the creation of more systems of open access and open publishing to scholarly writings. Instituting a new system of open access, however, comes with its own set of difficulties. In particular, it produces a whole new set of challenges for universities and especially for university librarians. His action research in the Swedish context, uncovers problems relating to the research culture, administration of knowledge databases, and legal issues, among others.

\section{Part 4: Panels}

The HCC8 conference includes three panels on three important contemporary topics: Free and Open Source Software (FOSS), policies relevant for large scale projects for the development of information systems infrastructures, such as for national health systems, and the potential of ICTs to improve women's lives.

In their panel Free and Open Source Software in low-income countries: emergent properties?, Gianluca Miscione, Dorothy Gordon, and Kevin Johnston 
draw from experiences of the development and use of open source software in Africa and India. There tends to be a revolutionary hype about FOSS as a way of constructing and acquiring software that is vital for development by liberating software producers and users from the constrains of conventional business models. These panellists, while recognizing the developmental potential of FOSS, go beyond hype to discuss some of the requirements for effective FOSS practice, with particular emphasis on mechanisms of organisational learning.

In the panel Evaluating 'Connecting for Health': policy implications of a UK mega-programme, Jane Hendy, Ela Klecun, Kathy McGrath, Leslie Willcocks, and Terry Young draw lessons from a 10 year mega-project intended to implement an integrated ICT infrastructure in the UK National Health Service (NHS). As the panel description points out, "fully informatized" health care is a vision that all countries consider desirable, but no country has realized. The pannelist discuss various difficulties that have been slowing down, increasing costs and, in some cases, inhibiting the implementation of the UK NHS ICT programme.

In Gender research in Africa into ICTs for empowerment, Ineke Buskens, Gertrudes Macueve, Ibou Sane, and Ann Webb present and discuss the rationale, methodology and findings of GRACE, a three year research project studying the implications of the gender divide and the way it inhibits the potential benefits of ICTs for development in Africa. In addition to the overall presentation of GRACE as an international NGO initiative, the panel includes discussions of findings from some of its 14 sub-projects, including a study of women's use of telecentres and mobile phone networks in rural Mozambique and a study of the use of mobile telephony by women fishmongers and fish processors in Senegal.

\section{Conclusions}

The chapters of this book demonstrate the multiplicity and complexity of interrelated issues that confront policy action intended to foster visions of the information or knowledge society. Many of these issues are studied in longstanding IFIP working groups, such as WG9.4 on ICT in developing countries, and receive attention in the biennial World IT Forum (WITFOR) of IFIP. Several other learned organisations and NGOs are also engaged in research and debate on aspects of policy that shape features of the information society.

The book demonstrates also current collective capacity of such research forums to articulate policy related issues and address them, at least analytically. Clearly, more research effort is needed, theoretically and empirically, to understand the unfolding socio-technical processes. More specifically, we need to achieve better understanding of the way through which existing social institutions, such as government mechanisms at national and international levels, NGOs and the market can contribute to the formation of socio-economic regimes that translate technology innovation to improvements of human life conditions, such as reducing poverty and delivering education that enhances human capabilities. 
As we complete this book of proceedings three months ahead of the HCC8, we hope that this event will stimulate such further research, debate, and action.

\section{References}

[1] Arora, A. \& Gambardella, A. (Eds.) (2005). From underdogs to tigers: The rise and growth of the software industry in Brazil, China, India, Ireland, and Israel. Oxford: Oxford University Press.

[2] Asheim, B.T. \& Gertler, M.S. (2005). The geography of innovation: Regional innovation systems. In Fagerberg, J., Mowery D.C., and Nelson, D. (Eds.) The Oxford handbook of innovation. (pp. 291-317). Oxford: Oxford University Press.

[3] Avgerou, C., Ciborra, C., \& Land, F. (Eds.) (2004). The social study of information and communication technology. Oxford: Oxford University Press.

[4] Avgerou, C. \& McGrath, K. (2005). Rationalities and emotions in IS innovation, in Howcroft, D. \& Trauth, E.M. (Eds). Handbook of critical information systems tesearch: Theory and application. (pp. 299-324). Cheltenham: Edward Elgar.

[5] Bauman, Z. (1988). Legislators and Interpreters. Cambridge: Polity Press.

[6] Berleur, J., Nurminen, M.I. and Impagliazzo, J. (Eds.) (2006). Social informatics: An information society for all? In remembrance of Rob Kling. New York: Springer.

[7] Bijker, W.E. \& Law, J. (Eds.) (1992). Shaping technology/building society. Cambridge, Massachusetts: MIT Press.

[8] Cantwell, J. (2005). Innovation and competitiveness. (2005). In J. Fagerberg, D.C. Mowery, and D. Nelson (Eds.) The Oxford handbook of innovation (pp. 543-567). Oxford: Oxford University Press.

[9] Ciborra, C. (2006) The mind or the heart? It depends on the (definition of) situation. Journal of Information Technology. 21(3), 129-139.

[10] Clement, A. \& Van den Besselaar, P. (1993). A retrospective look at participatory design projects. Communications of the ACM, 36(4), 29-37.

[11] Commander, S. (Ed.) (2005) The software industry in emerging markets. Cheltenham: Edward Elgar.

[12] Coopey, R. (Ed.) (2004). IT Policy: An international history. Oxford: Oxford University Press.

[13] Edquist, C. (1997). Systems of innovation: Technologies, institutions, and organizations. London: Pinter.

[14] English, M. \& Watson Brown, A. (1984). National policies in information technology: Challenge and responses. Oxford surveys in information technology. 1, 55-128.

[15] Giddens, A. (1984). The constitution of society. Outline of the theory of structuration. Cambridge: Polity Press.

[16] Kahin, B. \& Wilson, E. (Eds.) (1997). National information infrastructure initiatives: Vision and policy design. Cambridge, Massachusetts: MIT Press.

[17] Kling, R., Rosenbaum, H., \& Sawyer, S. (2005) Understanding and communicating social informatics: A framework for studying and teaching the human contexts of information and communication technologies. Medford, NJ: Information Today.

[18] Law, J. (Ed.) (1991). A sociology of monsters: Essays on power, technology and domination. London: Routledge.

[19] Lazonick, W. (2005). The innovative firm. In J. Fagerberg, D.C. Mowery, and R.R. Nelson (Eds.) The Oxford handbook of innovation (pp. 30-55). Oxford: Oxford University Press. 
[20] Lundvall, B.-Å. (Ed.) (1992). National systems of innovation: Towards a theory of innovation and interactive Learning. London: Pinter.

[21] Mansell, R. \& Steinmueller, W.E. (2002). Mobilizing the information society: Strategies for growth and opportunity. Oxford: Oxford University Press.

[22] Mumford, E. \& Sackman, H. (Eds.) (1974). Human choice and computers. Amsterdam: North-Holland.

[23] Van den Besselaar, P. (1998) Technology \& democracy, the limits to steering. Proceedings of the participative design conference: Broadening participation. Seatle: CPSR.

[24] Williams, R., Stewart, J., \& Slack, R. (Eds.) (2005). Social learning in technological innovation. Cheltenham: Edward Elgar. 